\title{
Professional Writing Tips and Techniques
}

\section{COMMUNICATION CORNER No. 18}

\section{by Philip Yaffe}

\section{Editor's Introduction}

Each "Communication Corner" essay is self-contained; however, they build on each other. For best results, before reading this essay and doing the exercise, go to the first essay "How an Ugly Duckling Became a Swan," then read each succeeding essay.

Good writing is not easy, but these 12 tips and techniques makes things easier. 


\title{
Professional Writing Tips and Techniques
}

\author{
COMMUNICATION CORNER No. 18
}

\section{by Philip Yaffe}

The first several "Communication Corner essays" (1-8) extensively covered the fundamental principles of effective expository writing (and by extension effective speaking). We can now take a close-up look at some specific tips and techniques. However, these specific tips and techniques can be successfully applied only if the fundamental principles of expository (non-fiction) writing and speaking are kept uppermost in mind. Otherwise, as they say in French, your efforts to write well and speak well will be like "putting a cast on a wooden leg" (mettre un plâtre sur une jambe de bois).

It is a good idea to consciously review these fundamental principles when actually inputting at the keyboard, i.e. regularly ask yourself "Why do I want to do what I am about to do?" Or "Why did I do what I just did?" To help focus your mind, here are the principles of expository writing in a nutshell.

\section{Fundamental Purpose}

- Expository writing is designed to inform and instruct.

\section{Fundamental Attitude}

- No one wants to read what you are going to write.

- First and foremost, you must give them reasons for doing so.

\section{Fundamental Approach}

- Organize information to generate interest.

Definition of Clarity: $C_{L}=E D E$

- Emphasize what is of key importance

- De-emphasize what is of secondary importance

- Eliminate what is of no importance

\section{Definition of Conciseness: $\mathrm{C}_{0}=\mathrm{LS}$}

- Long as necessary

- Short as possible

Definition of Density: $\mathrm{D}=\mathrm{PL}$

- Precise information

- Logically linked 


\section{Inverted Pyramid}

- Lead: Who? What? When? Why? How?

- Body: Detailed information in declining order of importance

\section{SPECIFIC TIPS AND TECHNIQUES}

\section{Fog Factors}

Unnecessary words in a text cause fog (reduced clarity). Eliminate them.

Fog: On the one hand the box was big and on the other hand it was green Clarity: The box was big and green

Fog: When we take into account those factors that have an effect on the economy .... Clarity: Concerning economic factors .... .

Fog: In the last place on the list ....

Clarity: Finally ....

Remember: Nothing in a text is neutral. Whatever doesn't add to the text, subtracts from it.

\section{Sentence Length}

Contrary to popular belief, a logically constructed long sentence can be easier to understand than several shorter ones. ("Long" and "short" are weasel words, because what is long in one situation is short in another.)

Check "long" sentences for logical coherence.

- If the ideas are closely related, leave the sentence alone.

- If not, divide it into logically coherent shorter ones.

Check "short" sentences for logical linkage.

- If the ideas in several sentences are closely related, put them together into a single sentence.

- If not, leave them separate. 


\section{Placement for Emphasis}

Words at the beginning and at the end of a sentence have stronger emphasis than those in the middle. These are known as "hot spots." Put key information into these hot spots to aid reader understanding. Here are two examples of how to improve placement.

\section{Example 1}

Poor: Astronomers hunting for evidence of life outside of our solar system announced discovery of a new class of planets yesterday.

Better: Yesterday astronomers hunting for evidence of life outside of our solar system announced discovery of a new class of planets.

Best: Astronomers hunting for evidence of life outside of our solar system yesterday announced discovery of a new class of planets.

\section{Example 2}

Poor: The national leaders met to discuss new trade relations between their two countries in the Royal Palace.

Better: In the Royal Palace the national leaders met to discuss new trade relations between their two countries.

Best: The national leaders met in the Royal Palace to discuss new trade relations between their two countries.

While hot spots exist in English, they may not exist in certain other languages or are differently located in a sentence. If you are not writing in English, check to see if your language also has hot spots. If yes, then fully exploit them on all possible occasions. If not, check to see if the language contains some other feature that could be used like hot spots. Since emphasis is fundamental to communication, chances are good that it does.

\section{Separation for Emphasis}

Separate a key idea from a longer sentence for dramatic impact.

Poor: Only a few years ago, we were a small specialty manufacturer in Europe, but we have grown, so that today we are no longer small.

Better: Only a few years ago, we were a small specialty manufacturer in Europe, but we have grown. Today we are no longer small.

Separation can also be used with paragraphs, which may lead to single-sentence paragraphs. Although more acceptable today than in the recent past, some grammarians and conventional writers would still say that single-sentence paragraphs violate some kind of grammatical "rule." 
However, professional writers increasingly ignore this so-called rule when doing so boosts clarity; dramatic effect and clarity often go hand-in-hand.

You have already seen many examples of paragraph separation throughout the Communication Corner series. Here are two of them.

\section{Example 1}

\section{Conventional writing}

Over the past 40 years, I have frequently been told that I am an exceptionally good writer, by teachers, friends, colleagues, and clients. But I wasn't always a good writer; in fact, I used to be a very bad one.

So what happened to bring about this monumental change? Basically, university. When I was growing up (I was born in 1942), I was a very unusual kid. I absolutely loved school. I was especially fond of math and science; I never really thought about writing. However, when I went from primary to secondary school, I quickly realized that writing would become increasingly important. So being the bizarre kid I was, I decided to teach myself how to do it.

\section{Professional writing}

Over the past 40 years, I have frequently been told that I am an exceptionally good writer, by teachers, friends, colleagues, and clients. But I wasn't always a good writer; in fact, I used to be a very bad one.

So what happened to bring about this monumental change? Basically, university.

When I was growing up (I was born in 1942), I was a very unusual kid. I absolutely loved school. I was especially fond of math and science; I never really thought about writing. However, when I went from primary to secondary school, I quickly realized that writing would become increasingly important. So being the bizarre kid I was, I decided to teach myself how to do it.

\section{Example 2}

\section{Conventional writing}

You may now feel that the inverted pyramid is an excellent idea-for newspapers. But is it relevant for the type of writing that you do? Emphatically, yes! Remember, the inverted pyramid provides information in exactly the way people prefer it, particularly when they are in a hurry. 


\section{Professional writing}

You may now feel that the inverted pyramid is an excellent idea-for newspapers. But is it relevant for the type of writing that you do?

Emphatically, yes!

Remember, the inverted pyramid provides information in exactly the way people prefer it, particularly when they are in a hurry.

\section{Parentheses and Dashes for Emphasis}

Use parentheses (these are parentheses) to incorporate explanatory or secondary information into a sentence.

Use dashes - these are dashes - to highlight exceptionally important information within a sentence.

\section{Example}

Newspapers used to be published infrequently (weekly rather than daily) and had very few pages. When they became dailies - with some even having several editions every day-they no longer had time to rewrite stories to fit the space for them on the page.

\section{Repetition for Clarity}

Don't be afraid to repeat a word for clarity and emphasis. Continually changing terminology causes hesitation and reduces clarity.

Poor: The big dog looked at me strangely. I am afraid of large canines, so I cautiously moved away.

Better: The big dog looked at me strangely. I am afraid of big dogs, so I cautiously moved away.

If you wish to use more than one term to mean the same thing, be certain that you clearly inform the reader.

Poor: Atopic dermatitis is a common disease of infants aged 0-2 years. About half of all infants with infantile eczema will develop asthma before their fourth birthday.

Better: Atopic dermatitis (infantile eczema) is a common disease of infants aged 0-2 years. About half of all infants with infantile eczema will develop asthma before their fourth birthday.

\section{Avoid Using the Conjunction "and"}


The conjunction "and" is like an equal sign, indicating that the two ideas it connects have essentially the same weight. However, often they don't; one idea is more important than the other. Make this relationship explicit; don't expect the reader to do it.

Poor: It started to rain and John went into the house.

Better:

It started to rain, so John went into the house.

It started to rain; therefore John went into the house.

Because it started to rain, John went into the house.

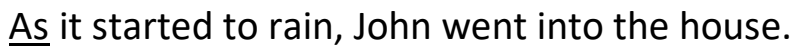

When it started to rain, John went into the house.

\section{Active versus Passive Verb Forms}

Use active verb forms rather than passive ones to create a sense of immediacy.

Example: We have just been in a difficult period.

Not: We have just gone through a difficult period.

"Just gone through" is active because "to go" is an action. The active verb strongly confirms that the difficult period is now over.

"Just been in" is passive because "to be" is a state or condition. The passive verb less strongly confirms that the difficult period is now over.

\section{Verbs for Conciseness and Density}

Use verbs rather than nouns to increase conciseness and density.

Example: The new product will strongly contribute to increasing profits.

Not: The new product will be a strong contributor to an increase in profits.

\section{Bullet Points and Numbered Lists}

Use bullet points or numbered lists to explain and highlight general statements. Bullet points or numbers that relate to nothing have no value. In other words, first state a proposition, then show bullet points or a numbered list to support it.

\section{Example}

These are the four factors that led us to this decision:

1. Economic conditions are...

2. Technical developments have...

3. Government policy will ... . 
4. Social conditions are...

These are the four factors that led us to this decision:

- Economic conditions are...

- Technical developments have...

- Government policy will .. .

- Social conditions are ...

Make bullet points and numbered lists "clean." The purpose of bullet points is to make thoughts and information stand out. So why go against the current by not capitalizing the first letter of each point?

\section{Version A}

Our system helps people:

- write better;

- write faster;

- write persuasively;

- reduce errors;

- reduce formatting problems.

\section{Version B}

Our system helps people:

- Write better

- Write faster

- Write persuasively

- Reduce errors

- Reduce formatting problems

Note that in addition to capitalizing each bullet point, Version B also eliminates the semicolons and the period. What logic is there for putting in commas, semicolons, and periods? The fact that the next line is a new bullet point, i.e. clearly a new thought, makes such punctuation unnecessary, and therefore distracting.

Arrange listed items to start with a verb or key word. Starting each item of a list with a verb or a key word increases impact and facilitates understanding. Starting each item passively or with a minor element of little or no significance reduces impact and impedes understanding.

\section{Poor}

There are many advantages to assertive communication:

- It helps us feel good about ourselves and others. 
- It leads to the development of mutual respect with others.

- It increases our self-esteem.

- It helps us achieve our goals.

\section{Better}

There are many advantages to assertive communication. It:

- Helps us feel good about ourselves and others

- Helps us achieve our goals

- Leads to development of mutual respect with others

- Increases our self-esteem

"It" is a limp term. Using it at the beginning of each bullet point diminishes the impact and understanding we want such a list to achieve. Using it only once in the introduction to the list does a much better job.

Since each bullet point now takes the form of a phrase rather than a complete sentence, we can eliminate the periods at the end, which now serve no real purpose.

\section{How to Display Data}

Display data directly next to their reference. Data displayed "respectively" requires the reader to stop and confirm the correct order.

Poor: The CAC, DAX, and AEX all fell during past three months: $-1.76 \%,-0.98 \%$, and $-2.26 \%$ respectively.

Better: The three indices that fell during the past three months were: CAC $(-1.76 \%)$, DAX ($0.98 \%)$, and AEX (-2.26\%).

When readers backtrack to confirm data, you lose mind control (attention). By displaying data properly, you maintain mind control (attention). The word "respectively" almost always causes loss of mind control. Banish it from your vocabulary.

\section{Writing and Re-writing}

The first draft and the revised draft are two distinctly different phases of good writing. Do them separately; do not try to do both at the same time.

\section{First draft}

- Focus on structure and content

- Write the way you speak, i.e. rapidly put the content into the structure without too much concern for how you are writing. 


\section{Revised draft(s)}

- Focus on clarity, conciseness, density

- Correct grammar, vocabulary, wordiness, poorly placed info, etc.

Leave a few hours (or days) between the first draft and the revised draft. During this so-called "incubation period," your subconscious mind will continue thinking about the text while your conscious mind is focused somewhere else. When you do work on the revised draft, you will be more efficient. You will produce a much better text in much less time than if you try to do the two phases simultaneously or one immediately after the other.

Good writing is not easy. . . but it gets easier.

\section{MATHEMATICAL MAGIC}

In the previous installment (CC17), I showed you an extremely simple trick that baffles many people who believe they know something about mathematics. I said as a computer scientist or programmer, you should be better than others at figuring out how this trick works. Why? Most people know we use a number system based on powers of 10, but don't really understand what this means, largely because they never work in any other bases. You do - the base two. Given this practical exposure to another base, you are probably more attuned to unraveling this mystery than people who have not had this exposure.

I didn't show the trick because it is an apparent demonstration that it is possible to read minds via the internet. Instead, I gave you the URL.

As a reminder, you are asked to:

Think any two-digit number from 10 to 99 (e.g. 54).

Subtract from the number its two digits (e.g. $54-5-4=45$ ).

Find the symbol in the provided chart that corresponds to this result.

Concentrate on the symbol in your mind for a few seconds. Then click on the magic square, and the symbol you are concentrating on will appear.

\section{How It Works}

The fact that we use a decimal number system means that any number can be represented by a combination of powers of 10 . Specifically, any two-digit number can be represented as $10 \mathrm{X}+\mathrm{Y}$. 
Following the instructions for the calculation, i.e. subtract the two digits from the number, gives $10 X+Y-Y-X=10 X-X=9 X$.

In other words, no matter what two-digit number you choose, when you do the calculation, the result will always be a multiple of nine. Look at the chart and you will see that all multiples of nine are associated with the same symbol. So no matter what number you choose, after the prescribed calculation, the associated symbol will always be the same.

Of course, each time you try it on the website, the symbol associated with multiples of nine changes, but the principle remains: All multiples of nine are associated with the same symbol.

Here is another number base trick.

The participant shuffles an ordinary deck of 52 cards to be certain they are well mixed. He then chooses 27 cards at random and gives you them to you. Put aside the remaining cards; they won't be needed.

You then say, "Incidentally, do you have a lucky number or favorite number between 1 and 27 ? Or simply pick any number between 1 and 27 at random." He does so and tells you what it is (e.g. 8).

You then deal out the 27 cards face up into three columns. You do this by first putting down one card at the left, one in the middle, one at the right, then starting over again - left, middle, right-until all 27 cards are in three columns on the table.

$\begin{array}{llll}\mathrm{x} & & \mathrm{x} & \mathrm{x} \\ \mathrm{x} & & \mathrm{x} & \mathrm{x} \\ \mathrm{x} & . . & . . & \\ . . & . . & . . & \\ . . & . . & . . & \end{array}$

You then say, "Think of any one of the cards. Don't tell me what it is, but fix it firmly in your mind. Do you have your card fixed firmly in mind? Good. Now which column is it in?" The participant tells you. You pick up the cards and do the same thing again, i.e. deal out three columns left to right face up. Then ask the participant, "Which column is your card in now?" He tells you. You do the procedure a third time, i.e. deal out three columns, ask the participant in which column his card is located, then pick up the cards.

Now say, "What was the number between 1 and 27 you chose at the beginning?" He answers: eight. From your hand, you deal out seven cards face down. You then deal out the eighth card face up. "Is this the card you chose?" It is the King of Hearts, indeed the card he chose. And there is amazement all around. 
I won't describe how the trick works. Some things are better explained visually than verbally. For the explanation, please go to YouTube.

\section{HOMEWORK: Retrospective to Communication Corner No. 17}

There is no retrospective to CC17.

\section{CURRENT HOMEWORK}

The following is the transcript of a presentation made to an international business group in Brussels (Belgium). It was amply supported by a series of well-constructed slides, so it is interesting to see how well it would have stood up as a naked presentation, i.e. without visual support. The numbers in parentheses refer to the Analysis at the end of the text.

\section{How to Do This Exercise}

1. Cover the page so that only the text of the speech is visible and read the text.

2. As you read, make notes about what you think the numbers in parentheses are trying to point out about how the speech was prepared.

3. Uncover the analysis and compare it with your notes.

There is an old Anglo-Saxon marketing maxim that says: "If you build a better mousetrap, the world will beat a path to your door." In more common language, if you have a better product, people will seek you out to buy it (1). But only if they know you have a better product. This is the role of marketing, or more specifically marketing communication.

Everyone in business in some way practices marketing communication. The problem is, even marketing communication specialists really don't know what they are doing (2). They have strong opinions about what they are doing (3), but if you put two such experts together, their strong opinions are likely to go in exactly opposite directions (4).

This is because many practitioners still believe that marketing communication such as advertising and press relations is more of an art than a science. You need to "feel" advertising and press relations. It is true that certain people are more sensitive than others, and therefore probably do a better job. However, they are mistaken in the belief that "feel" is the principal factor for success (5).

Marketing communication is a science (6). I would like to investigate some of the key principles of this science, with some examples to make them clear (7). 
These are not my principles (8). I'm not going to tell you what seems to have worked for me and suggest you do the same thing. These principles are based on and confirmed by solid scientific research. And they are all contained in a very readable book that I strongly recommend anyone interested in effective marketing communication should read. Its title is Tested Advertising Methods by John Caples. It is called Tested Advertising Methods (9) because over a 50-year period, Mr. Caples actually ran scientific experiments to find out what really works and what doesn't. Some of his findings are very surprising and are directly contrary to what most people believe (10).

[The presentation continues...]

\section{Analysis}

1. This marketing maxim would probably be unfamiliar to most listeners in an international audience, so the question is: "What does it mean?" The answer comes immediately in the following sentence.

The presenter opens his presentation this way for two reasons:

- $\quad$ Raising an unexpressed question in the first sentence heightens listener interest.

- Listeners may hear the maxim again sometime in the future, so they will now know what it means.

2. A rather surprising statement, which again heightens interest.

3. Notice the use of repetition for emphasis.

- $\quad$ what they are doing

- $\quad$ strong opinions

4. The question is: "Why should this be the case?" The answer comes immediately in the following sentence.

5. Notice repetition of the word "feel" for emphasis.

6. This is an example of the "separation technique." The speaker could have said: "However, they are mistaken in the belief that feel is the principal factor for success, because marketing communication is a science." Instead, he chose to say "Marketing communication is a science" as a separate sentence for greater emphasis.

7. This statement tells the listeners exactly what will be in the body of the presentation, so they are prepared for it. 
8. Apparently a very banal statement, but it partially answers the question: "Who says marketing communication is a science?" The full answer comes in the rest of the paragraph.

9. Separation and repetition for emphasis. The speaker could have said: "Its title is Tested Advertising Methods because over a 50-year period author John Caples actually ran scientific experiments to find out what really works and what does not." Instead, the speaker wisely chose to use two sentences and to repeat Tested Advertising Methodsprobably with vocal emphasis on the word "tested."

10. Once again the speaker tells the listeners what will be in the body of the presentation. This time he strengthens his hold on their attention with a teaser. What thinking person wouldn't want to know which cherished ideas they hold that science has now challenged or disproved?

I think you will agree this quite easily could have been delivered without slides or other visual aids, i.e. a naked presentation. This is often the best way to develop a presentation. If it can succeed without visual aids, it will almost certainly be better with them. If it cannot succeed without visual aids, it probably needs to be revised.

\section{About the Author}

Philip Yaffe was born in Boston, Massachusetts, in 1942 and grew up in Los Angeles, where he graduated from the University of California with a degree in mathematics and physics. In his senior year, he was also editor-in-chief of the Daily Bruin, UCLA's daily student newspaper. He has more than 40 years of experience in journalism and international marketing communication. At various points in his career, he has been a teacher of journalism, a reporter/feature writer with The Wall Street Journal, an account executive with a major international press relations agency, European marketing communication director with two major international companies, and a founding partner of a specialized marketing communication agency in Brussels, Belgium, where he has lived since 1974 . He is the author of more than 30 books, which can be found easily in Amazon Kindle.

DOI: $10.1145 / 3366380$ 